\title{
Analysis of soil nutrients and their simultaneous effect to human health in terms of toxicity: A pilot study
}

\author{
Vatsal Chopra $^{1, *}$, Abhijay Pandita ${ }^{2}$, Rushil Bhairok ${ }^{3}$, Mahua Chakraborty ${ }^{4}$, Purushottam Sharma $^{5}$ \\ ${ }^{1,2,3}$ Student, ${ }^{1}$ Scottish High International School, Gurugram, ${ }^{2}$ Ryan International School, New Delhi ${ }^{3}$ The Shri Ram School, \\ Aravali, ${ }^{4}$ Additional Director, Forensic Science, ${ }^{5}$ Director, Supreme Testing Lab and Forensic Evidence Protection Technology \\ Pvt. Ltd (STEP), New Delhi, India
}

*Corresponding Author:

Email: chopra.vatsal@gmail.com

\begin{abstract}
Soil contains a wide variety of mixtures including organic matters, minerals, nutrients required by plants. These nutrients are directly or indirectly related to human health. Soil is an important source of nutrients in our food supply. These types of imbalances in nutrients can cause negative effects on health. Soil provides many of the nutrients we require and can pass on harmful substances through the intake of food. Supply of any element may result in human toxicity even though the elements are essential for life. For any essential element there is an optimal range of concentration in humans, falling below this optimal range results in deficiency, whereas concentrations above the optimal range create toxicity. Soil mostly found near the industrial areas is dangerously contaminated with minerals like Sulphur, Boron, and Phosphorus etc. Also uncontrolled use of high quantity of fertilizers without having awareness and knowledge of their negative effects would also lead to toxicity. So, production of fruits, vegetables and crops on such contaminated soils prove to be dangerous to human health. Soil samples from twenty different areas (industrial as well as non-industrial areas) where native people grow plants for production of food were targeted, analysis of which have resulted in the extraction and detection of high levels of minerals. Chronic consumption of food from plants grown in such contaminated soils is one of the important and main reasons for negative health effects leading to toxicity and eventually increases the chance of mortality rates in humans.
\end{abstract}

Keywords: Soil, Nutrients, Minerals, Fruits, Vegetables, Consumptions, Toxicity, Humans.

\section{Introduction}

Soil consists of

a mixture of organic matters, minerals, gases, liquids and organisms that in combinations support life. It is a medium for plant growth, water storage, supply, purification and is a modifier of Earth's atmosphere. The physical properties of soils for crop production are texture, structure, bulk density, porosity, consistency, temperature, color and resistivity. The essential elements would be present in the right proportions for healthy growth of the plant throughout. However, in the process of cultivation of plants, soil may require the addition of organic or inorganic fertilizers. Soil is a major and most important source of nutrients for plant growth. Nutrients supplied by the soil are called mineral nutrients. The nonmineral nutrients such as carbon $(\mathrm{C})$, hydrogen $(\mathrm{H})$ and oxygen $(\mathrm{O})$ come from air and water sources during photosynthesis. Soil mineral nutrients are divided into two group's viz. the macro and micronutrients. The macro nutrients are further divided into two groups the primary and the intermediate nutrients. The primary nutrients are required by plants in relatively large proportions and include nitrogen $(\mathrm{N})$, phosphorus $(\mathrm{P})$ and potassium $(\mathrm{K})$. The intermediate nutrients which are required by plants in medium quantities include calcium $(\mathrm{Ca})$, magnesium $(\mathrm{Mg})$ and sulphur $(\mathrm{S})$. The micronutrients required by the plants in relatively small proportions include iron ( $\mathrm{Fe})$, boron (B), manganese $(\mathrm{Mn})$, copper $(\mathrm{Cu})$, zinc $(\mathrm{Zn})$, molybdenum (Mo), nickel $(\mathrm{Ni})$ and chlorine $(\mathrm{Cl})$. Though the soil nutrients are separated into different groups but each nutrient is equally important. ${ }^{1}$

Flowchart 1: Showing types of nutrients (minerals) required by plants

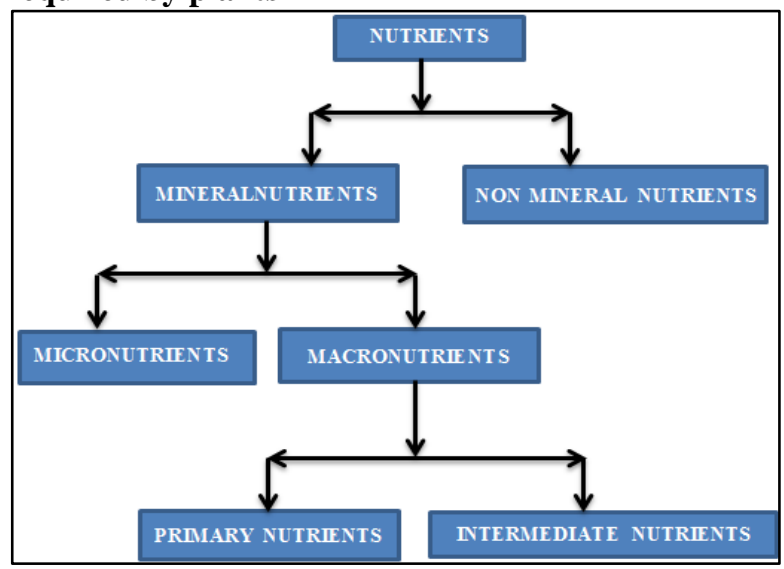

Changes due to various factors such as crop harvesting, leaching, erosion, fixation, volatilisation, addition of fertilizer, manure, compost and deposition and absorption of industrial contaminants occur in soil which affect the quantity and availability of nutrients. So, soil should be tested for its ability to supply nutrients required for growth of the plants. The soil test aids in revealing the nutrient contents. Another important factor is that soil has a considerable effect on human health, whether those effects are positive or negative, direct or indirect. Soil is an important source 
of nutrients in our food supply. These types of nutrient imbalances can cause negative effects on health. Soil provides many of the nutrients we require and can pass on harmful substances through the intake of food. Supply of any element may result in human toxicity even though the elements are essential for life. For any essential element there is an optimal range of concentration in humans, falling below this optimal range results in deficiency, whereas concentrations above the optimal range create toxicity. There are 14 elements essential for plant growth that comes from the soil, and many of these elements are also essential for human health. ${ }^{2}$ These essential nutrients

human diet directly by the consumptions of plants or its products. ${ }^{3}$ Hydrogen, oxygen, carbon, nitrogen, sodium, potassium, calcium, magnesium, phosphorous, sulphur and chlorine make up $99.9 \%$ of the atoms in the human body, with all but hydrogen, oxygen and carbon having soil as their major source. ${ }^{4}$ However, the remaining $0.1 \%$ consists of approximately 18 additional elements known as micronutrients or trace elements that are essential in small amounts to maintain human health. ${ }^{2}$ So, soils providing plants with the proper nutrients for growth also contain many of the elements that are necessary for human health as well.

The idea that human health is tied to the soil is not a new one. As far back as circa 1400 BC the Bible depicts Moses as understanding that fertile soil was essential to the well-being of his people. Soils and human health studies include investigations into nutrient supply through the food chain. ${ }^{5}$ Soil describes the general condition or quality of the soil resource. Organic matters contribute to maintenance of nutrient cycling and soil structure. Sequestration of $\mathrm{C}$ in soil also plays some role in regulating the emission of greenhouse gases such as methane and carbon dioxide. Factors as $\mathrm{pH}$, bulk density and soil organic matter content determine the prevailing condition of the habitat within the range for a particular soil. Agricultural soils have been altered from their natural state by human interventions which are aimed at maximizing production functions and which, to some degree, always result in a loss of other ecosystem functions. ${ }^{6}$ Studies have shown that long-term land application of $\mathrm{P}$ as fertilizer and animal wastes has resulted in elevated levels of soil $\mathrm{P}$ in many locations in the United States of America. ${ }^{7}$ Food security could only be attained with increasing crop productivity. One of the major crop productivity constraints is the unavailability of crop nutrients. Both macro and micro nutrient deficiencies have been reported in most of the soils, which could be provided through various nutrient management practices. ${ }^{8}$

Health of humans is affected by the world's soils. Soils influence a variety of functions (e.g. as a plant growth medium; its importance on the cycling of water; as a foundation for buildings) that supports the human population. Through ingestion (either deliberate or involuntary), inhalation and dermal absorption, the mineral, chemical and biological components of soils can either be directly beneficial or detrimental to human health. ${ }^{2}$

In reality, world people are exposed to mixtures, not single chemicals. Although various substances may have totally independent actions, in many cases two substances may act at the same site in ways that can be either additive or non-additive. ${ }^{9}$

\section{Material and Methods \\ Reagents and Chemicals}

\begin{tabular}{|l|l|}
\hline 1 & Potassium dichromate \\
\hline 2 & Sulphuric acid \\
\hline 3 & Sodium bicarbonate \\
\hline 4 & Ammonium molybdate \\
\hline 5 & Antymony Tartrate \\
\hline 6 & Ascorbic Acid \\
\hline 7 & Potassium Sodium Acetate \\
\hline 8 & Acetic Acid \\
\hline 9 & Morgan Reagent \\
\hline 10 & Sodium Tetraphenyl Boron \\
\hline 11 & Buffer Solutions, Anti-Flocculent \\
\hline 12 & Sodium Acetate \\
\hline 13 & Barium Chloride \\
\hline 14 & Hydrochloric acid \\
\hline 15 & Dithiozone \\
\hline 16 & Propanol-1 \\
\hline 17 & Salicyclic acid \\
\hline 18 & Trienthanol Amine \\
\hline 19 & Sodium Chloride \\
\hline 20 & Azomethine H \\
\hline
\end{tabular}

\section{Study Protocol \\ Sample Size}

Samples of soil are collected from 20 different areas (Industrial and non- industrial areas) of New Delhi, India. For each sample, 10 well distributed spots are targeted for sample collection. The soil samples from 10 distributed spots are mixed properly over clean sheets of paper. The bulk is reduced by quartering process. The soil is dried properly. The plant materials, residues, gravels etc. are removed. The soil samples are grinded properly. The entire quantity is then sieved through $0.3 \mathrm{~mm}$ sieve. The sieved samples are remixed thoroughly before performing the analysis. 
Table 1: Showing location of sample collection

\begin{tabular}{|c|c|l|}
\hline S. No & Sample Codes & \multicolumn{1}{|c|}{ Places of Collection } \\
\hline 1 & S1 & Mangolpuri Industrial Area \\
\hline 2 & S2 & Govindpuri \\
\hline 3 & S3 & Kattar Market, Mangolpuri \\
\hline 4 & S4 & Okhla Industrial Area \\
\hline 5 & S5 & Rohini \\
\hline 6 & S6 & Uttam Nagar \\
\hline 7 & S7 & Chandni Chowk \\
\hline 8 & S8 & Trans Yamuna Area \\
\hline 9 & S9 & Jahangirpuri \\
\hline 10 & S10 & Dwarka \\
\hline 11 & S11 & Ballimaran \\
\hline 12 & S12 & Janakpuri \\
\hline 13 & S13 & Mundka \\
\hline 14 & S14 & Bawana \\
\hline 15 & S15 & VivekVihar \\
\hline 16 & S16 & Wazirpur \\
\hline 17 & S17 & Mehruli-Gurgaon Road \\
\hline 18 & S18 & Rajouri garden \\
\hline 19 & S19 & AnandVihar \\
\hline 20 & S20 & Narela \\
\hline
\end{tabular}

\section{Parameters of Samples testing}

Examples of the soil parameters include amount of nutrients present in soil. The nutrients include both macronutrients and micronutrients. Examples of macronutrients include organic carbon, phosphorus $(\mathrm{P})$, potassium (K), and sulphur (S). Examples of micronutrients include zinc ( $\mathrm{Zn})$ and boron $(\mathrm{B})$.

\section{Instrumentation}

The soil parameter-testing unit includes one or more of photo-detector units. Further, the photodetector unit comprises of a lighting unit adapted to illuminate one or more soil samples. The lighting unit further comprises one or more light sources having illuminating different colors such red, blue, green, and combination thereof.
The photo-detector unit further includes a light sensing unit adapted to detect a light reflected or refracted from the soil samples when the light source illuminates the soil samples. ${ }^{10}$

\section{Sample Preparation}

Organic carbon (Non mineral nutrient), Phosphorus (Macro-primary nutrient), Potassium (Macro Primary nutrient), Zinc (Micro nutrient), Boron (Micro Nutrient), Sulphur (Macro intermediate nutrient) are extracted from the collected soils samples following the standard operating procedure mentioned below. Extraction and analysis is done for 3 consecutive days for each soil sample. 
Flowchart 2:

Extraction of Organic Carbon

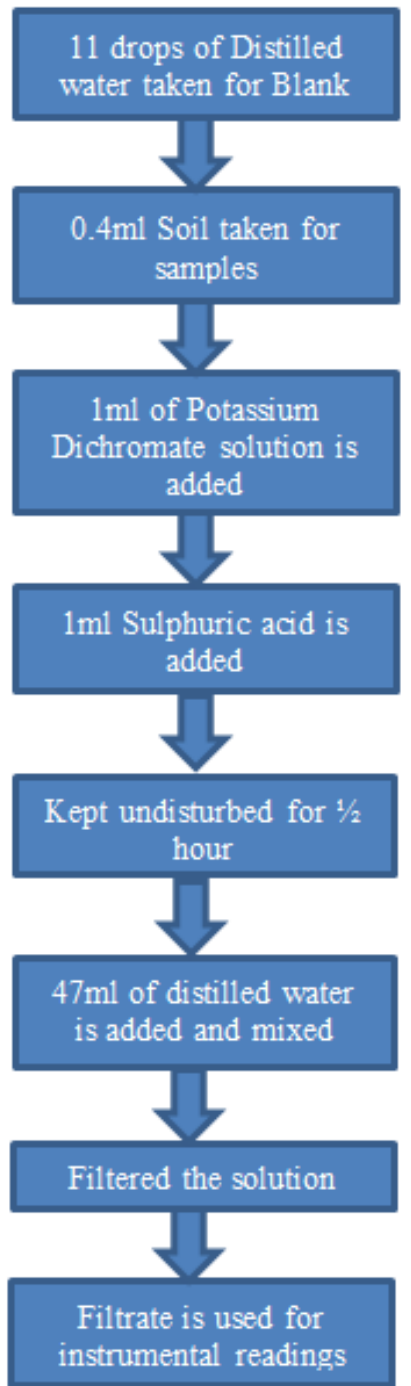

Flowchart 3: Extraction of Phosphorus

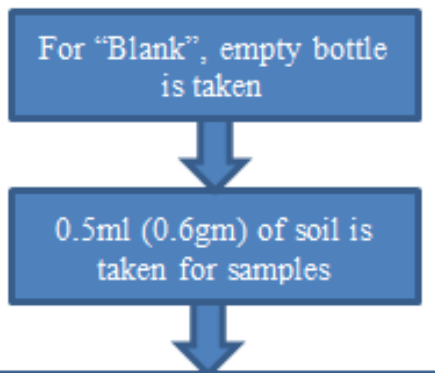

$12 \mathrm{ml}$ of Sodium Bicarbonate is added, followed by $0.3 \mathrm{ml}$ of Charcoal

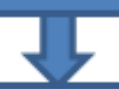

Extract is filtered

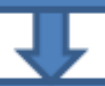

$2 \mathrm{ml}$ of filtrate is taken for color development

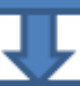

5 drops of Ammonium Molvbdate solution is added

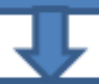

$2 \mathrm{ml}$ of Ascorbic acid is added followed by $1 \mathrm{ml}$ of Potassium Antimonv tartrate

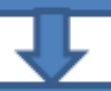

The extracts are used for instrumental readings
Flowchart 4: Extraction of Potassium

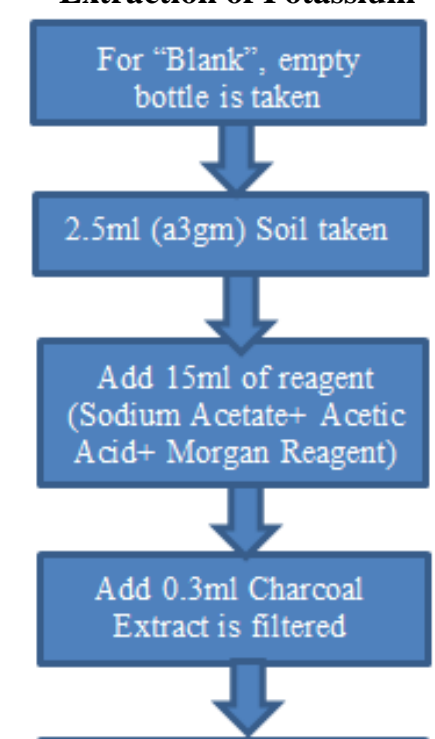

$1 \mathrm{ml}$ of Sodium Tetra phenyl Boron followed by

11 drops of buffer

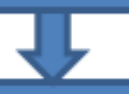

Test tubes are shaken slowly and then kept undisturbed for 3 mins

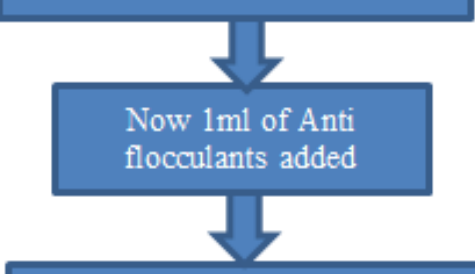

5 drops of seeding solution added quickly, waited for $1 \mathrm{~min}$, shaken slowiy and closed

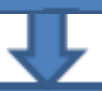

Added distilled water to $10 \mathrm{ml}$ mark, shaken up and down 3 times, kept aside for 5 mins

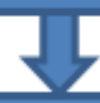

The extracts are used for instrumental readings 
Flowchart 5:

Extraction of Zinc

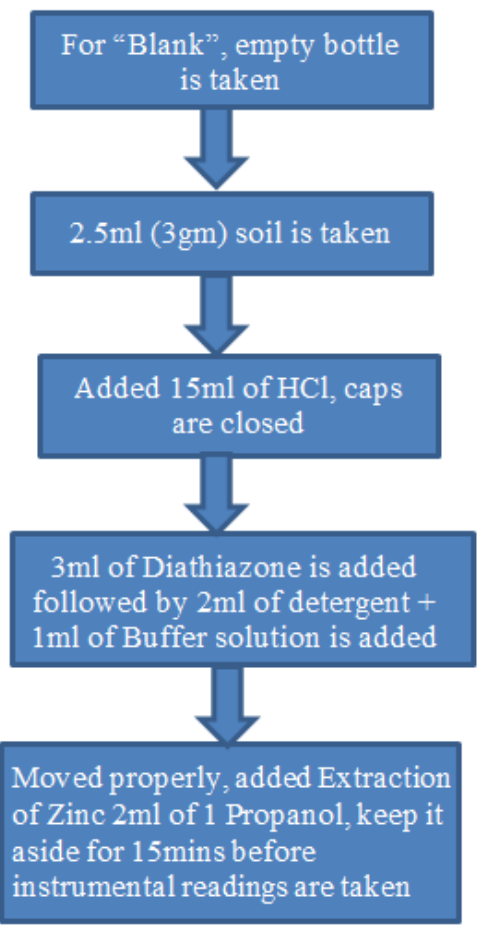

Flowchart 6:

Extraction of Boron

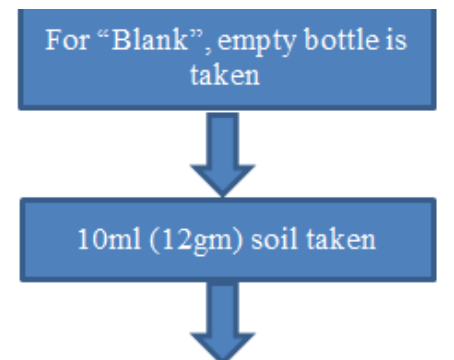

$24 \mathrm{ml}$ of reagent (Salicylic

acid, Trienthanol Amine +

Sodium chloride) added,

caps are closed

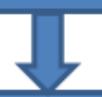

Extracts are filtered, $3 \mathrm{ml}$ filtrate is taken

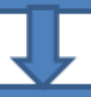

$1 \mathrm{ml}$ of Azomethine $\mathrm{H}+1 \mathrm{ml}$

Ascorbic acid is added, shaken

5 times, kept aside for 30 mins

before instrumental readings are
Flowchart 7:

Extraction of Sulphur

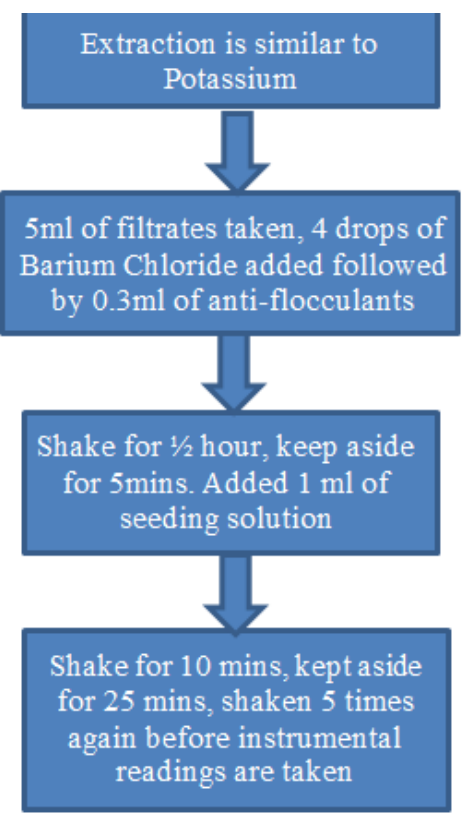

\section{Principle of sample preparation and instrumentation}

Soil parameter to be tested is the amount of nutrients present in the soil. The extraction reagent extracts the nutrient in the portion of soil. Thereafter, a color is developed by mixing color-developing reagent. Based on the selection of one or more nutrients, the data processing unit selects a light source in the photodetector unit for illuminating one or more soil samples. Accordingly, the light sensing unit in the photo-detector unit then measures light reflected/ refracted from the one or more soil samples as color intensity.

The measured color intensity is proportional to the amount of nutrient extracted in the soil sample.
Prior to performing soil testing on the soil samples, the user prepares a blank solution for each of the selected one or more nutrients to be tested. The blank solution is a solution in which no nutrient is present and is used as a negative control. The blank solutions are tested by the soil parameter-testing unit in a same manner the soil samples are tested. Upon testing the blank solutions, the soil samples are tested. The soil parameter-testing unit then determines value of the one or more soil parameter based on the color intensity measure for both the blank solution and the soil samples ${ }^{10}$.

\section{Result}

\begin{tabular}{|l|c|c|c|c|c|}
\hline & $\begin{array}{c}\text { Organic } \\
\text { Carbon= \%ge } \\
\text { Range=0-1.7\% }\end{array}$ & $\begin{array}{c}\text { Sulphur=mg/kg } \\
\text { Range=0-150 }\end{array}$ & $\begin{array}{c}\text { Potassium=kg/ha } \\
\text { Range=0-400 }\end{array}$ & $\begin{array}{c}\text { Boron=mg/kg } \\
\text { Range 0-5 }\end{array}$ & $\begin{array}{c}\text { Phosphorus=kg/ha } \\
\text { Range 0-80 }\end{array}$ \\
\hline Samples & Average & Average & Average & Average & Average \\
\hline S1 & 0.004233 & 215.5766667 & 123.6667 & 1.82 & 881.2333333 \\
\hline S2 & 0.0033 & 121.1533333 & 235.3333 & 3.543333333 & 876.9333333 \\
\hline S3 & 0.0031 & 77.54666667 & 256.4667 & 44.52333333 & 59.06666667 \\
\hline S4 & 0.002367 & 223.32 & 165.7667 & 4.54 & 828.6666667 \\
\hline S5 & 0.0026 & 142.8933333 & 333.4667 & 42.08 & 76.86666667 \\
\hline S6 & 0.003433 & 81.94 & 122.7333 & 87.75333333 & 832.9666667 \\
\hline S7 & 0.003567 & 225.5266667 & 175.0333 & 22.08666667 & 24.3 \\
\hline S8 & 0.002267 & 221.2833333 & 222.1333 & 4.2 & 842.9 \\
\hline
\end{tabular}




\begin{tabular}{|c|c|c|c|c|c|}
\hline S9 & 0.002267 & 281.8866667 & 266.2 & 3.43 & 68.07333333 \\
\hline S10 & 0.001533 & 93.12333333 & 233.4667 & 1.536666667 & 85.6 \\
\hline S11 & 0.0016 & 233.0633333 & 213.7 & 27.56 & 93.5 \\
\hline S12 & 0.0016 & 54.056666667 & 252.3 & 2.68 & 103.7333333 \\
\hline S13 & 0.002767 & 62.22333333 & 343.9333 & 52.25333333 & 46.55 \\
\hline S14 & 0.0021 & 242.88 & 205.5 & 5.016666667 & 15.54 \\
\hline S15 & 0.0025 & 218.76 & 256.1667 & 56.04666667 & 810.7333333 \\
\hline S16 & 0.002433 & 272.1133333 & 246.1667 & 101.7533333 & 813.9333333 \\
\hline S17 & 0.0026 & 101.9933333 & 214.2667 & 54.7 & 72.23333333 \\
\hline S18 & 0.0026 & 132.0166667 & 288.0667 & 44.56666667 & 62.59666667 \\
\hline S19 & 0.0032 & 222.9566667 & 207.4667 & 47.23 & 801.6666667 \\
\hline S20 & 0.003333 & 301.6266667 & 216.2667 & 98.04333333 & 125.7333333 \\
\hline \multicolumn{6}{|c|}{$\begin{array}{l}\text { ZINC=mg/kg } \\
\text { Range 0-10 } \mathrm{mg} / \mathrm{kg}\end{array}$} \\
\hline S1 & 23.9 & & & & \\
\hline S2 & 22.56667 & & & & \\
\hline $\mathbf{S 3}$ & 23.66667 & & & & \\
\hline S4 & 34.76667 & & & & \\
\hline S5 & 43.96667 & & & & \\
\hline S6 & 48 & & & & \\
\hline S7 & 35.4 & & & & \\
\hline S8 & 36.5 & & & & \\
\hline S9 & 34.96667 & & & & \\
\hline S10 & 45.53333 & & & & \\
\hline S11 & 35.36667 & & & & \\
\hline S12 & 32.23333 & & & & \\
\hline S13 & 28.8 & & & & \\
\hline S14 & 37.1 & & & & \\
\hline S15 & 32.26667 & & & & \\
\hline S16 & 33.36667 & & & & \\
\hline S17 & 28.7 & & & & \\
\hline S18 & 48.86667 & & & & \\
\hline S19 & 42.23333 & & & & \\
\hline S20 & 43.36667 & & & & \\
\hline
\end{tabular}

Organic Carbon $=\%$ ge Range $=\mathbf{0}-1.7 \%$

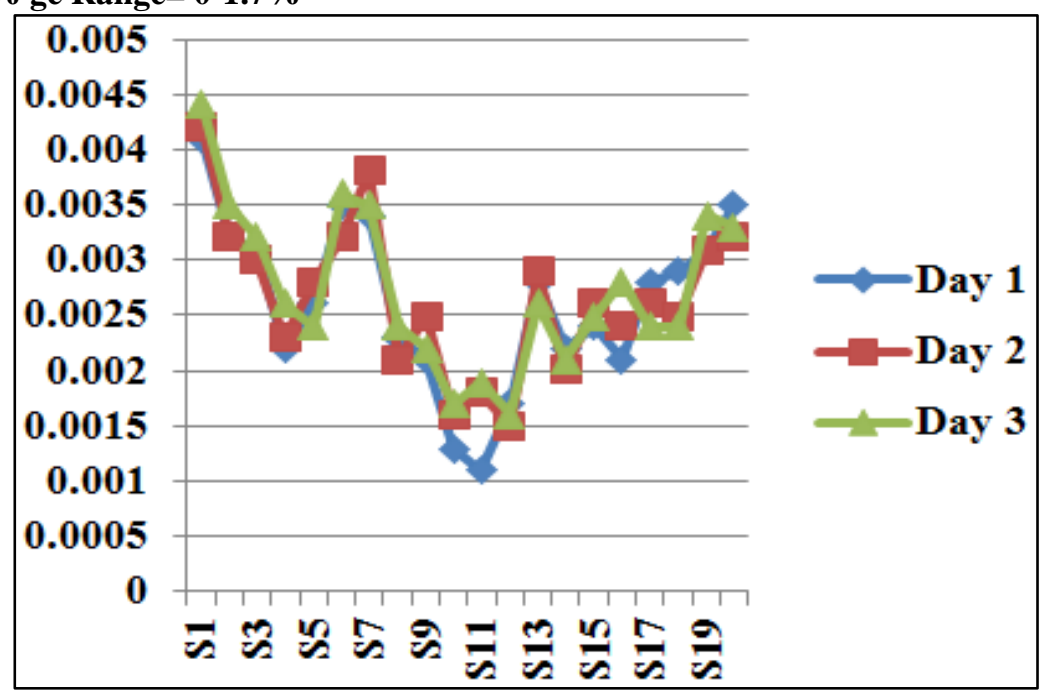

Fig. 1: 
Sulphur=mg/kg Range $=0-150$

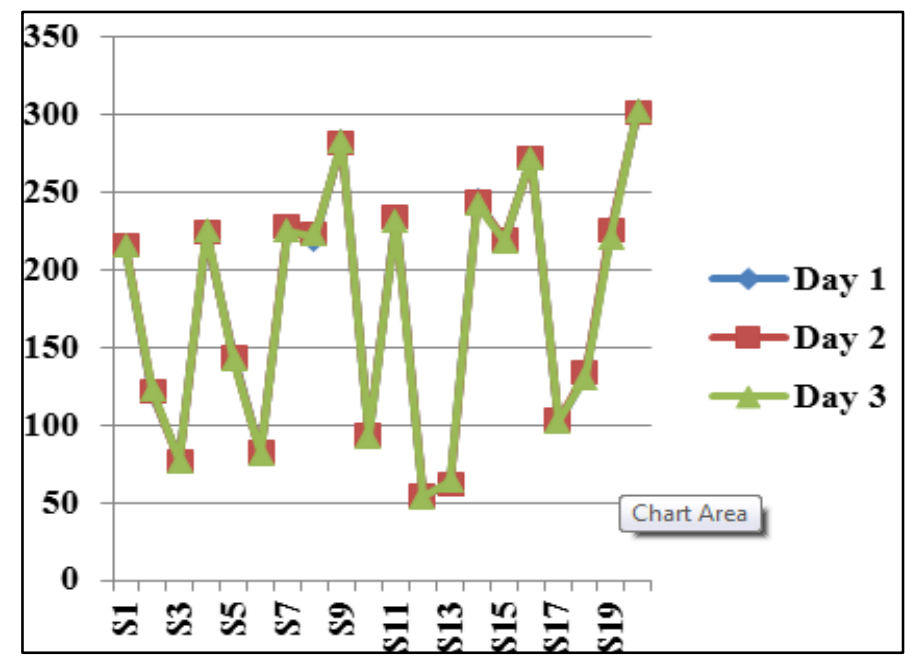

Fig. 2

Potassium $=\mathrm{kg} / \mathrm{ha}$ Range $=\mathbf{0}-400$

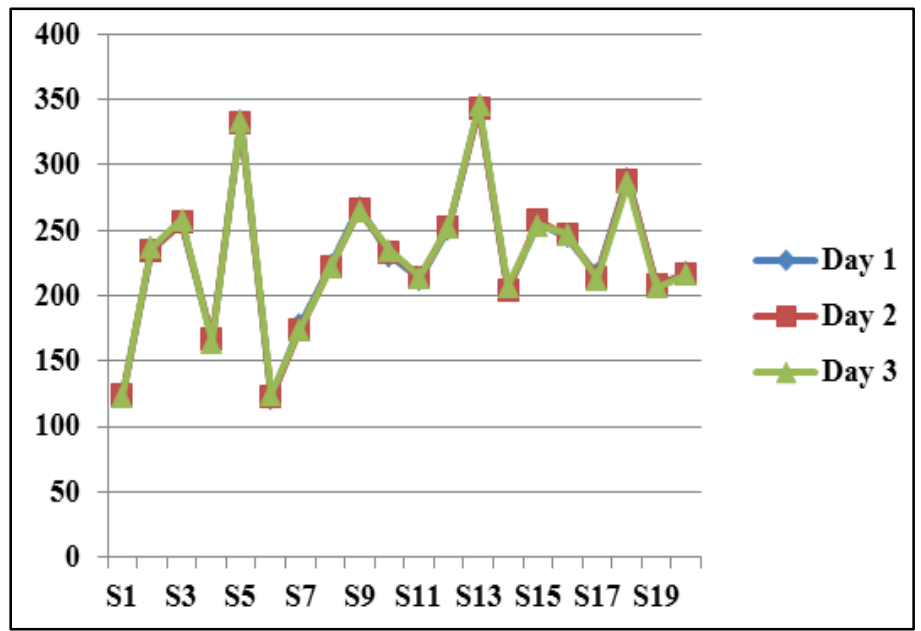

Fig. 3

Boron=mg/kg Range= 0-5

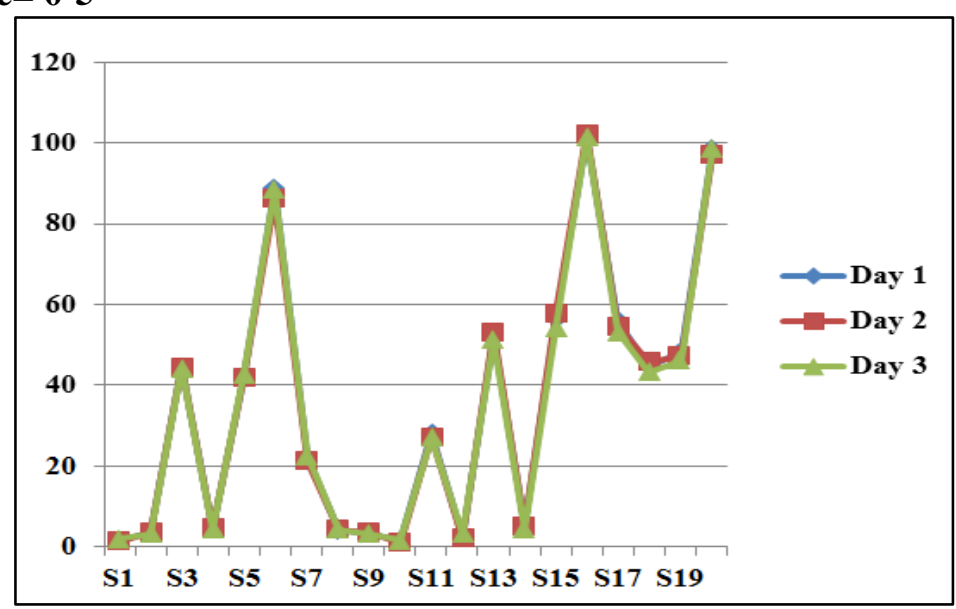

Fig. 4 


\section{Phosphorus=kg/ha Range 0-80}

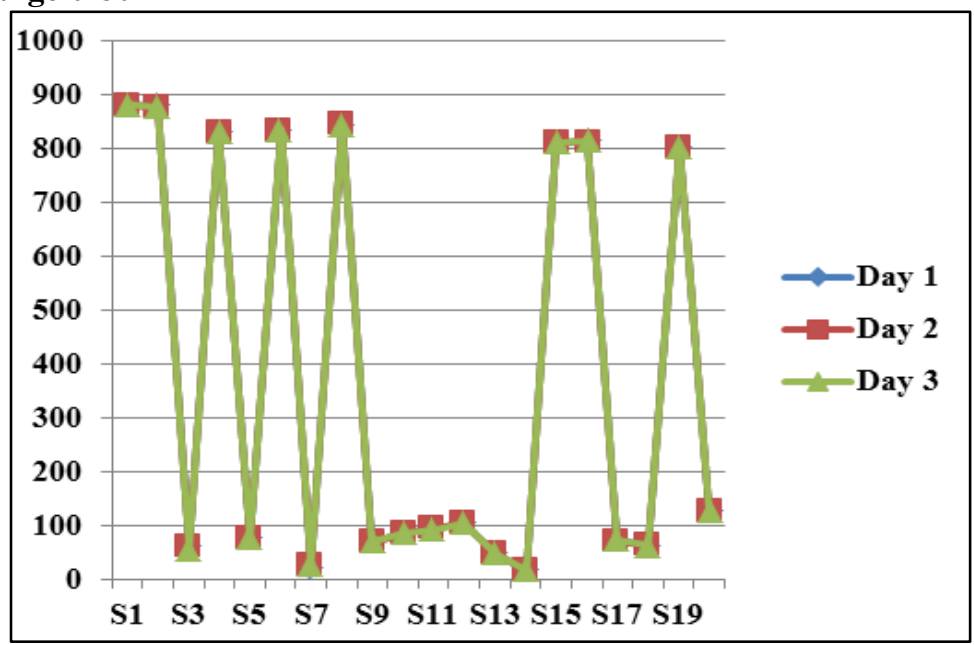

Fig. 5

\section{Zinc=mg/kg Range 0-10}

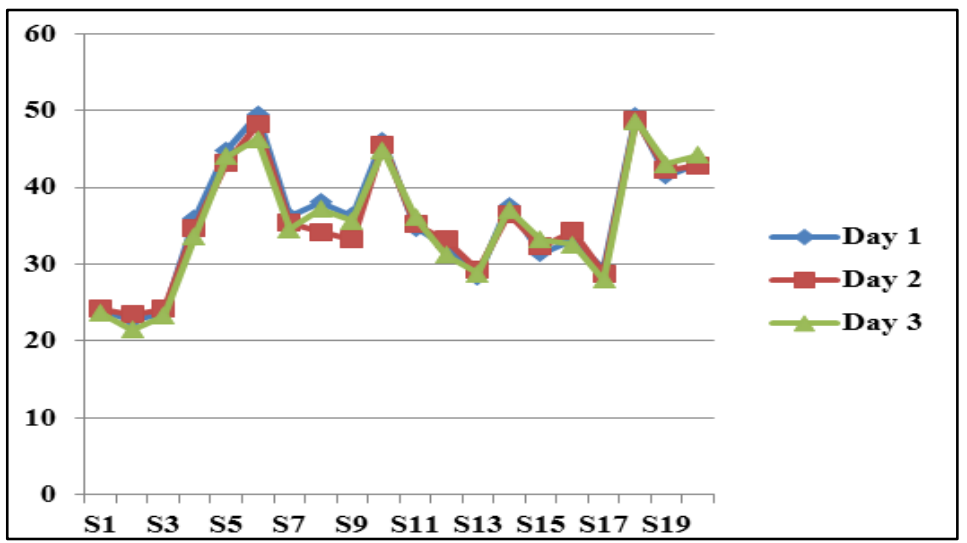

Fig.6

\section{Discussion}

Soil has a considerable effect on human health, whether those effects are positive or negative, direct or indirect. Soil is an important source of nutrients in our food supply. These types of nutrient imbalances can cause negative effects on health. Soil provides many of the nutrients we require and can pass on harmful substances through the intake of food. Supply of any element may result in human toxicity even though the elements are essential for life. For any essential element there is an optimal range of concentration in humans, falling below this optimal range results in deficiency, whereas concentrations above the optimal range create toxicity. ${ }^{3-4}$ Soils play a major role in all of these areas of quality food production and security. Exposure to heavy metals through soil contact is a major human health concern. ${ }^{12}$

Organic carbon (Non mineral nutrient), Phosphorus (Macro-primary nutrient), Potassium (Macro Primary nutrient), Zinc (Mico nutrient), Boron (Micro Nutrient), Sulphur (Macro intermediate nutrient) are extracted from the collected (20) soil samples.
Out of 20 soil samples, all samples showed presence of high amount of Zinc $(0-10) \mathrm{mg} / \mathrm{kg}$. Zinc $(\mathrm{Zn})$ is an essential micronutrient for normal healthy growth in plants, animals and humans that uptake as a divalent cation $(\mathrm{Zn} 2+)$ by plants. Zinc is playing principal metabolically role in plants. Zinc absorption capacity is reduced by high phosphorus utilization and zinc in plant and soil has an antagonism state with phosphorus (negative interaction), therefore zinc utilization is essential to obtain high yield and quality in crops. ${ }^{11}$ Out of 20 soil samples, 11 samples showed high Sulphur content, 9 samples showed presence of Sulphur within normal range i.e $(0-150) \mathrm{mg} / \mathrm{kg}$. Sulfur from all sources must either be in the sulfate form or be converted to the sulfate form before it can be used by plants. As mentioned above, organic matter is the major reservoir of sulfur in most soils. Except for sulfur fertilizers and irrigation water, the other sources listed contribute minor amounts. This high content of sulfate indicates high levels of air contamination with $\mathrm{SO} 2$ around the refinery which 
negatively effects the environment and public health that this populated area. ${ }^{13}$ Sulfur is one of the essential elements in all living things including plants. About 95 percent of the total sulfur content of most soils is contained in the organic matter which is broken down and is mineralized into the sulfates. Sulfate-sulfur can then be taken up by the roots of growing plants. Most of the fuels that are burned for heat, power and transportation contain some sulfur. When these fuels are burned, the sulfur escapes as sulfur dioxide gas $\left(\mathrm{SO}_{2}\right)$. Sulfur dioxide which gets dissolved in rainwater and reaches the soil as sulfate-sulfur, Sulfur dioxide in the atmosphere is highest in industrialized areas. Some of the pesticides also contain sulfur. Commercial fertilizers supplied considerable sulfur in addition to the nitrogen, phosphorus, and potassium. Irrigation water is also an important source of sulfur in some areas. ${ }^{14}$

Out of 20 soil samples, 12 samples showed presence of high amount of Boron, 8 showed Boron within normal range of $(0-5) \mathrm{mg} / \mathrm{kg}$. Naturally occurring Boron is a widely occurring element in minerals found in the earth's crust. Boron is found in the environment primarily combined with oxygen in oxygen to form compounds called borates. Boratecontaining minerals are mined and processed to produce borates for manufacture several industrial uses like industrial and consumer - glass and ceramics products - soaps, bleaches, and detergents - fire retardants - pesticides. Boron when enters the environment is released into air, water, and soil. Boron can be released from: - glass manufacturing plants • coal-burning power plants $\bullet$ copper smelters • agricultural fertilizer and pesticide usage. Exposure to boron can occur through food, mainly vegetables and fruits, as boron are an essential element in plants. The effect of boron on human health depends on how much boron is present, how you are exposed to it, and the length of exposure. Exposure to large amounts of boron over short periods of time can affect the stomach, intestines, liver, kidney, and brain and can eventually lead to death. ${ }^{15}$

Out of 20 soil samples, 8 samples showed presence of very high amount of Phosphorus, 4 samples showed presence of high amount of Phosphorus, 8 samples showed Phosphorus within normal range i,e, (0$80) \mathrm{kg} / \mathrm{ha}$. Concentrated phosphoric acids are used in fertilizers for agriculture and farm production. Phosphates are used for special glasses, sodium lamps, in steel production, in military applications (incendiary bombs, smoke screenings etc.), and in other applications as: pyrotechnics, pesticides, toothpaste, detergents. In the natural world phosphorous is never encountered in its pure form, but only as phosphates. There can be more phosphate in rivers and lakes, resulting in excessive algae growth. Phosphorus can be found in the environment most commonly as phosphates. Phosphorus can be found in the environment most commonly as phosphates. Humans have changed the natural phosphate supply radically by addition of phosphate-rich manures to the soil and by the use of phosphate-containing detergents. ${ }^{16}$

Zinc is an essential trace element that can cause symptoms of deficiency and can be toxic when exposures exceed physiological needs. Risks of zinc excess Toxic effects in humans are most obvious. Intentional or accidental ingestion of large amounts of zinc leads to gastrointestinal effects, such as abdominal pain, vomiting and diarrhoea. At high concentrations zinc can be cytotoxic. ${ }^{17}$

Out of 20 soil samples, Organic Carbon and Potassium recovered from all 20 soil samples were found to within normal range i.e. $(0-1.7) \%$ and $(0-$ 400) $\mathrm{kg} / \mathrm{ha}$ respectively. Organic matter makes up just $2-10 \%$ of the soils mass but has a critical role in the physical, chemical and biological function of agricultural soils. Carbon is a measureable component of soil organic matter. Organic matter contributes to nutrient turnover and cation exchange capacity, soil structure, moisture retention and availability, degradation of pollutants, greenhouse gas emissions and soil buffering. Soil organic matter (SOM) is mainly composed of carbon, hydrogen and oxygen but also has small amounts of nutrients such as nitrogen, phosphorous, sulphur, potassium, calcium and magnesium contained within organic residues. ${ }^{18}$ Both nitrogen and phosphorus are constituents of the soil organic matter, but potassium is not. Soil organisms have a much lower requirement for potassium than plants do. Consequently, as organic residues decompose, most of the potassium is quickly released. The behavior of potassium in the soil is determined more by physical than by chemical or biological processes. ${ }^{19}$

\section{Conclusion}

The present research study has clearly shown the importance of quantity of nutrients found in the soil which is directly related to health of humans. Excess quantity of nutrients(minerals) in the soil are transported to the products i,e fruits and vegetables which in turn enters the food chain leading to toxicity to human health.

To improve the quality of soil, kitchen gardening in the industrial areas should be avoided. In the nonindustrial area as well as in the industrial area, the population residing in or nearer to these locations should opt for generating soil health cards where the soil samples can be collected and sent to the laboratory for analysis of the nutrient contents. Based on the soil health cards, nutrients to be added or avoided would be known which will help to overcome and control soil toxicity and deficiency as well to greater extent.

\section{References}

1. https://en.wikipedia.org/wiki/Soil. Accessed online on 03/08/18. 
2. Combs, (eds O. Selinus, B. Alloway, J.A. Centeno, R.B Finkel man, R. Fuge, U. Lindh et al.) G.F. Jr. (2005). Geological impacts on nutrition. In: Essentials of Medical Geology, pp. 161- 177.

3. Abrahams PW. Soils: their implications to human health. Sci Total Environ 2002;291(1-3):1-32.

4. Brevik, E.C. (2013). Soils and human health: an overview. In: Soils and Human Health (eds E.C. Brevik\& L.C. Burgess), pp. 29- 56. CRC Press, Boca Raton, FL.

5. Brevik, E.C. and T. J. Sauer (2015). The past, present and future of soils and human health studies.

6. M.G Kibble white, K Ritz, M.J Swift (2008). Soil health in agricultural systems. Philosophical transactions of the royal society B. DOI: 10.1098/rstb.2007.2178. 363, 685-701.

7. T. C. Daniel, A. N. Sharpley and J. L. Lemunyon (1998). Agricultural Phosphorus and Eutrophication: A Symposium Overview. Journal of Environmental Quality, 251-257.

8. Sajid Ali, A. Riaz Khan, Ghazal Mairaj, M. Arif, MehwishFidaand Saiqa Bibi (2008). Assessment of different crop nutrient management practices for yield improvement. Australian Journal of Crop Science Southern Cross Journals@ 2(3):150-157.

9. David O. Carpenter, Kathleen Arcaro, and David C (2002). Understanding the Human Health Effects of Chemical Mixtures. Environ Health Perspect. 2002 Feb; 110(Suppl 1): 25-42.

10. STFR Meter Manual.
11. Sayed Roholla Mousavi (2011). Zinc in Crop Production and Interaction with Phosphorus. Australian Journal of Basic and Applied Sciences, 5(9): 1503-1509, 2011 ISSN 1991-8178.

12. Brevik, E.C., Lynn C. Burgess (2014). The Influence of Soils on Human Health. Nature Education.

13. https://www.researchgate.net/publication/26623617. Accessed online on 03/08/18.

14. Sulfur Dioxide (SO2) Accumulation in Soil.... Available from: https://www.researchgate.net/publication/26623617_Sulf ur_Dioxide_SO2_Accumulation_in_Soil_and_Plant's_Le aves_around_an_Oil_Refinery_A_Case_Study_from_Sau di_Arabia [accessed Aug 13 2018]. Sulfur Dioxide (SO2) Accumulation in Soil and Plant's Leaves around an Oil Refinery: A Case Study from Saudi Arabia

15. https://www.atsdr.cdc.gov/toxprofiles/tp26-c1.pdf. Accessed online on 04/08/18.

16. . https://www.lenntech.com/periodic/elements/p.htm. Accessed online on 04/08/18

17. http://www.who.int/ipcs/publications/ehc/221_Zinc_Part_ 3.pdf. Accessed online on 05/08/18

18. https://www.agric.wa.gov.au/soil-carbon/what-soilorganic-carbon. Accessed online on 05/08/18

19. http://www.nofa.org/soil/html/potassium.php. Accessed online on $05 / 08 / 18$ 